\title{
Changes in the growth and reproduction of a clonal plant as a result of disruption of mycorrhizal network
}

\author{
Martyna Dominiak-Świgoń1, Zbigniew Kasprzykowski² \& Marlena Lembicz ${ }^{1 *}$
}

\section{Article info}

Received: 22 Jul. 2021

Revision received: 22 Jul. 2021

Accepted: 27 Sept. 2021

Published: 31 Dec. 2021

\section{Associate Editor}

Elżbieta Cieślak

\begin{abstract}
In a clonal network, a mother plant is connected with daughter ramets. During network development, new ramets may encounter barriers that disrupt network integrity. As a result, resource allocation within a network is disturbed. In this study, the effect of network integrity disruption on the size of ramets and their sexual reproduction was investigated in mouse-ear hawkweed (Hieracium pilosella). Three types of networks were formed experimentally with unlimited resource allocation, with limited resource allocation between a mother plant and its daughter ramets and with limited resource allocation between all ramets. Networks were either supported by the presence of a mycorrhizal fungus or restricted by its absence. We found that the size of the mother and the effectiveness of sexual reproduction did not differ among network types. The length and dry mass of runners were higher in cases with limited resource exchange between a mother plant and its daughters. In the clonal plant network without any barriers to connection, a higher number of rosettes and lower dry mass of daughters were recorded. The mean number of daughter flowers did not differ among the network types. Mycorrhizal network is one of the most important factors for the sexual reproduction of clonal plants. With a reduced mycorrhizal network, plants invested in clonal growth.
\end{abstract}

Key words: fungus, guerrilla growth, Hieracium pilosella, meta-holobiont, resource allocation

\section{Introduction}

Many types of organisms form network structures in nature. Many vascular plant species that are clonal plants form networks (van Groenendael \& de Kroon 1990). These networks consist of interconnected units (ramets) (Harper 1977). Ramets are connected by rhizomes or runners. The length and frequency of connections differ depending on the species (Lovett-Doust 1981; Harper 1986). Thus, two growth forms can be identified in clonal plants: phalanx and guerrilla. The phalanx growth form is characterized by short, strongly branched connections, while in the guerrilla growth form, the connections are longer and more weakly branched (Lovett-Doust 1981; Harper 1986). The growth form of an individual may change depending on the habitat and the individual's age (e.g., Pirożnikow 1993; Li et al. 2015).

\footnotetext{
${ }^{1}$ Adam Mickiewicz University, Faculty of Biology, Department of Systematic and Environmental Botany, Poznań, Poland (Lembicz, ORCID: 0000-0003-1714-4716; Dominiak-Świgoń, ORCID: 0000-0001-8021-8891)

2 Siedlce University of Natural Sciences and Humanities, Faculty of Natural Science, Department of Environmental Studies and Biological Education, Siedlce, Poland

* Corresponding author e-mail: lembicz@amu.edu.pl
}

Each ramet in a network is capable of independent life (Jackson et al. 1985). In this case, why do they live in a network? A network enables the optimization of resource distribution through allocation. A mother plant transfers water and mineral salts to its offspring and, in return, receives assimilates (Stuefer et al. 1996; de Kroon \& Van Groenendael 1997). This type of physiological integration of ramets in a network increases ramet productivity by up to $70 \%$ (Huber \& Stuefer 1997). Obtaining high-quality resources is more advantageous than using low-quality resources. Therefore, the division of labor increases the efficiency of the clonal plant network. It is particularly essential in habitats that are highly differentiated in terms of varying resource availability (Alpert \& Stuefer 1997). Success in obtaining resources depends on the size, shape and spatial distribution of root absorption zones (Fitter \& Hay 1989) and is determined by the root distribution in resource-rich habitats with low competition (Pechácková et al. 2003).

The water and nutrient uptake, as well as the resource allocation, within a network are modified by mycorrhizal fungi (e.g., Du et al. 2009). Over $80 \%$ of land plants participate in mycorrhizal relationships (Wang \& Qiu 2006; Smith \& Read 2008). Plants involved in interactions 
with mycorrhizal fungi benefit from a more substantial supply of phosphorus and nitrogen than that of plants that do not form mycorrhizal interactions (Van Der Heijden et al. 2003; Vogelsang et al. 2006). In turn, mycorrhizal fungi access the carbohydrates produced by the host plant (Miller et al. 2002). The inoculation of clonal plants with mycorrhizal fungi increases their vegetative reproduction, which is applicable in the cultivation of species such as Fragaria ananassa (Varma \& Schuepp 1994) and Fragaria vesca (Cassells et al. 1996). Studies by Streitwolf-Engel et al. (1997, 2001); Sudová and Vosátka (2008) and Sudová (2009) showed that various co-occurring arbuscular mycorrhizal fungi (AMF) may have, in addition to positive effects, negative effects on the vegetative reproduction of a plant. Vannier et al. (2016) also showed that the effects of plant interaction with AMF differed depending on the species of fungi. Inoculation modifies not only vegetative reproduction, but also the rate of growth, the length of inter-ramet connections, and the ramet biomass.

Previous studies of resource allocation in clonal plants that have relationships with fungi have not considered the whole network of ramets. Usually, two-ramet systems have been studied (e.g., Du et al. 2009). In such cases, only the amount of resources transferred between a mother and its daughter ramets, and vice versa, was evaluated. However, in naturally occurring networks, there is also a transfer of resources among daughter ramets. Resources in a given ramet are transferred according to the division of labor sensu Stuefer et al. (1996) both to a mother ramet and to a new daughter ramet. Furthermore, after some period of time, the network contains not one, but many mother ramets, i.e., the former daughter ramets that, as a result of their vegetative growth, became mothers of new daughter ramets. Each daughter ramet may become a mother for subsequent ramets due to clonal growth. Depending on the network structure, one mother ramet may produce either one daughter ramet [linear structure, e.g., in Carex arenaria (Noble et al. 1979)] or many daughter ramets (circular structure, e.g., in Hieracium pilosella).

Experiments based on two-ramet systems do not take into account the changes over time during the development of a network, such as the shift in ramet function - from the daughter to mother role - and changes in the size of resource availability zones. These changes are important in the uptake, transport and allocation of resources. Thus, only the evaluation of resource allocation within the whole network may show the distribution of resources to sexual reproduction and clonal growth. In our study, we considered all ramets within a network. This network contained a single mother ramet originating from a seed and its daughter ramets produced by clonal growth. We tested the hypothesis that the disruption of network integrity will disturb resource allocation within this network and, as a result, it will affect the size of ramets and their sexual reproduction. We expected that the size of particular plant components (dry mass of a mother, dry mass of runners and dry mass of daughter ramets), the development of clonal structures (the number of rosettes and length of runners) and the extent of reproduction (the number of mother and daughter flowers) would be highest when all the connections between ramets are preserved and supported by a mycorrhizal network.

\section{Material and methods}

\section{The study species}

Mouse-ear hawkweed, Hieracium pilosella, is a perennial plant in the daisy family (Asteraceae) that is indigenous to Europe and parts of Asia and invasive in North America, Australia and New Zealand (Beaumont et al. 2009). The leaves are gathered into a rosette at the base, from which a leafless stem sprouts to a height of 5-30 cm. The stem is usually crowned with a single inflorescence. After ripening, the flower head of the stem contains purple-black achenes. H. pilosella proliferates sexually via seeds and vegetatively using aboveground runners that grow out of axillary meristems. A rosette of leaves develops on the top of the runner and subsequently takes root. The plant may reproduce further vegetatively or produce seed-bearing flowers (Bishop \& Davy 1985). H. pilosella prefers the guerrilla growth form, with a mother plant in the center of the expanding network and daughter plants encircling it, forming a round spatial pattern.

\section{Description of the experiment}

The material, achenes of $H$. pilosella, was obtained from Poznań (GPS 52²8'03.5"N, 16 ${ }^{\circ} 55^{\prime} 26.4^{\prime \prime} \mathrm{E}$ ). Achenes were collected separately from 30 networks of mouseear hawkweed and from all inflorescences within each network. Next, 10 achenes were randomly selected from each pool of seeds. The achenes were surface-sterilized in sodium hypochlorite and ethanol and subsequently placed in dishes with agar medium (1.4\%). The dishes were placed in a phytotron chamber where they were illuminated for $16 \mathrm{~h} /$ day with the temperature maintained at $21^{\circ} \mathrm{C}$ during the day and $15^{\circ} \mathrm{C}$ at night at $60 \%$ humidity. After 20 days, 30 young seedlings of the same age were transferred to autoclaved soil combined with steamed soil inoculated with the mycorrhizal fungus Rhizophagus irregularis (Schenck and Smith). R. irregularis was in the form of spores and originated from the laboratory of Plant-Microbial Interaction Research Group, Institute of Environmental Sciences, Jagiellonian University, Kraków, Poland. Every plant received $4 \mathrm{~g}$ of fungal inoculate that contained 35 fungal propagules mixed with the soil. The plants were transferred to miniature greenhouses in order to maintain high humidity for 2 weeks, thereby preventing seedling death. After this time, 6 of the seedlings were transferred into 6 trays and 12 of the seedlings were transferred into 12 pots. The trays, measuring $50 \mathrm{~cm} \times$ $36 \mathrm{~cm} \times 8 \mathrm{~cm}$, were filled with a total of $12.6 \mathrm{~L}$ of soil. The pots, measuring $8 \mathrm{~cm} \times 8 \mathrm{~cm} \times 7 \mathrm{~cm}$, were filled with a total of $0.45 \mathrm{~L}$ of soil. The distribution of seedlings to trays and pots enabled the cultivation of the plants under semi-natural conditions with either unlimited or limited resource exchange between a mother plant and its daughter ramets and between all ramets within a network (Fig. 1). 


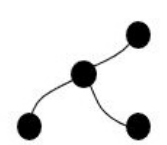

Type I - mother plant produces vegetative progeny; ramets are connected aboveground by runners, and underground trough a common mycorrhizal network.

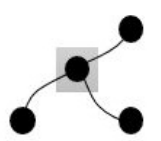

Type II - mother plant produces vegetative progeny; ramets are connected aboveground by runners; no underground connection of mother with progeny by AMF.

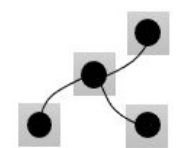

Type III - mother plant produces vegetative progeny; ramets are connected aboveground by runners; no underground connection of ramets by AMF.

Figure 1. Diagram of the cultures of the three types of $H$. pilosella (Type I-III) networks. There were six networks of $H$. pilosella of each type.

To prevent the overgrowth of mycelium and roots outside the pots/trays, the pots/trays were additionally secured with plastic foil. The growth material was kept under uniform conditions in the phytotron chamber throughout the duration of the culture. The soil was steamed three times at $90^{\circ} \mathrm{C}$ and, next, autoclaved at $121^{\circ} \mathrm{C}$. H. pilosella culture was maintained until new inflorescences had fully developed, i.e., 5 months.

\section{Measurements}

The length of the cultured seedlings was measured prior to planting them in the AMF-inoculated soil. The date of planting was considered day 1 of the culture. After the period of blooming and vegetative growth, the plants were removed from the soil and cleaned. Next, the following measurements were taken: the dry mass of the mother, number of mother flowers, dry mass of runners, length of runners, number of rosettes, dry mass of daughter ramets and number of daughter flowers (Tab. 1). The number of inflorescences produced by daughter ramets was presented jointly for each network. The dry mass was obtained by placing the material in a laboratory dryer at $60^{\circ} \mathrm{C}$ for 12 hours. After the first drying cycle, the samples were weighed, dried again for 30 minutes and reweighed. The procedure was repeated until the last measurement was equal to the previous measurement. In addition, throughout the culture, generative shoots were cut to evaluate how many inflorescences were produced by each mother and daughter ramet.

Table 1. Plant measurements were taken into consideration in analyzing the effects of network types.

\begin{tabular}{l|c|c|c|c}
\hline Variable & $\mathrm{N}$ & Mean & SE & Min-Max \\
\hline Dry mass of mother [g] & 18 & 1.072 & 0.1801 & $0.121-2.581$ \\
Number of mother flowers & 18 & 5.6 & 0.71 & $1-11$ \\
Dry mass of runners [g] & 376 & 0.434 & 0.0337 & $0.008-4.593$ \\
Length of runner [cm] & 377 & 88.9 & 5.873 & $1.6-806.7$ \\
Number of rosettes & 18 & 22.2 & 4.37 & $7-70$ \\
Dry mass of daughter [g] & 1122 & 0.210 & 0.0081 & $0.004-2.404$ \\
Number of daughter flowers & 18 & 32.1 & 10.63 & $0-147$ \\
\hline
\end{tabular}

\section{Statistical analyses}

The network types were classified as three categorical factors: type I, with underground connections between the mother plant and daughter ramets; type II, with underground connections only among the ramets; and type III, without underground connections between the mother and daughters. The influence of the network on the size and sexual reproduction of the studied plants was examined using one-way ANOVA and a post hoc Tukey's test. To approximate a normal distribution, all parameters were logarithmically transformed. The values reported are the means and standard errors. Only those results that showed a probability of $\alpha \leq 0.05$ were considered statistically significant. All statistical analyses were carried out using Statistica 12.0 (StatSoft Inc. 2018).

\section{Results}

All studied mother plants had flowers and created clonal structures. A higher total number of flowers (45) was recorded in the first category of plant networks than in the second (30) and third categories (26). However, the differences in the mean values of the number of mother flowers and the mother dry mass among network types were not significant (Tab. 2). In cases with limited resource exchange between a mother plant and its daughters (type II network), the length of runners was significantly higher than that for type I (post hoc Tukey test $p=0.005$ ) and type III (post hoc Tukey test $p=0.037$, Fig. 2). This parameter described the development of the

Table 2. Results of one-way ANOVA explaining the impact of network types on plant measurements.

\begin{tabular}{l|l|r|r}
\hline Variable & \multicolumn{1}{|c|}{$d f$} & $F$ & \multicolumn{1}{c}{$P$} \\
\hline Dry mass of mother & 2.15 & 3.87 & 0.144 \\
Number of mother flowers & 2.15 & 2.50 & 0.288 \\
Dry mass of runners & 2.373 & 5.41 & 0.005 \\
Length of runner & 2.374 & 5.26 & 0.006 \\
Number of rosettes & 2.15 & 5.52 & 0.016 \\
Dry mass of daughter & 2.1119 & 9.64 & $<0.001$ \\
Number of daughter flowers & 2.15 & 0.39 & 0.822 \\
\hline
\end{tabular}

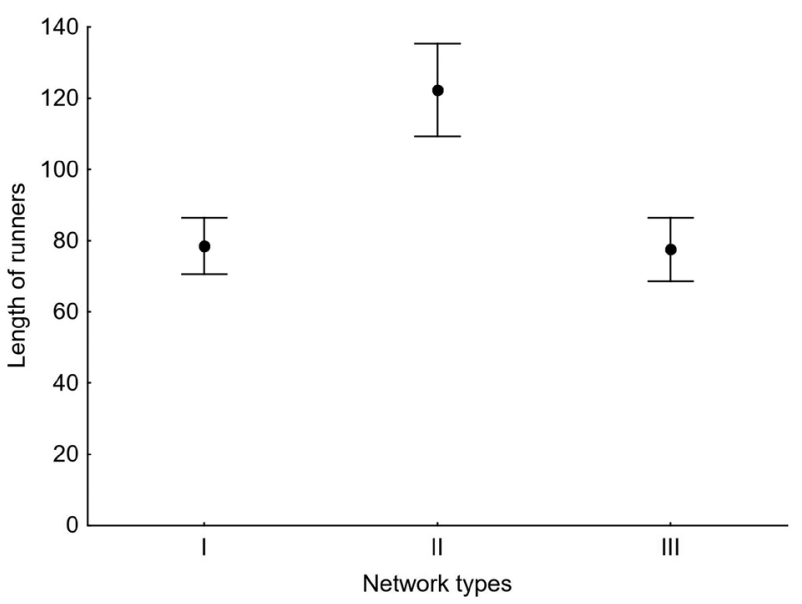

Figure 2. Mean (point) and standard error (whiskers) of runner lengths in the three network types. 


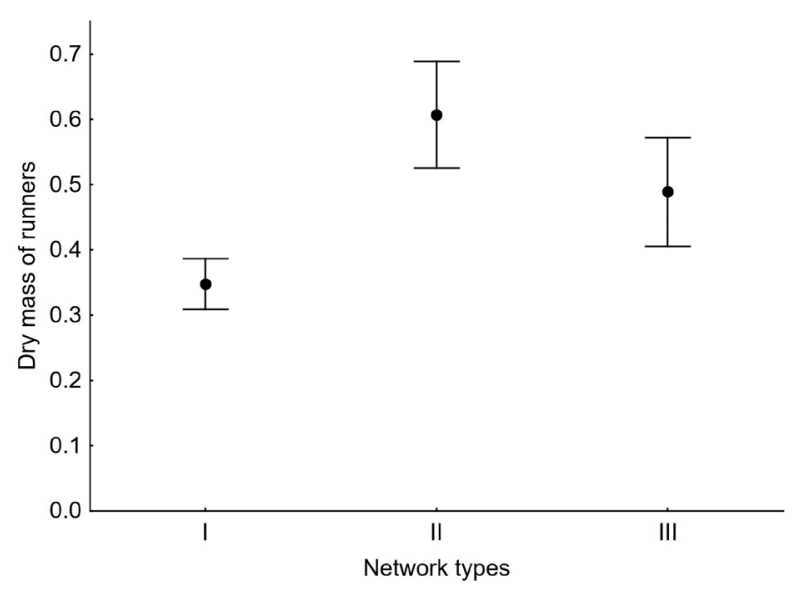

Figure 3. Mean (point) and standard error (whiskers) of runner dry masses in the three network types.

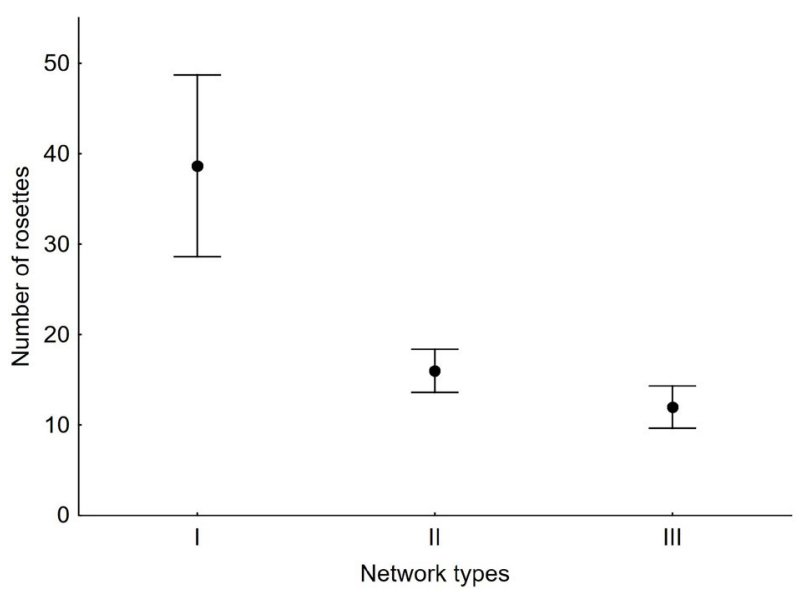

Figure 4. Mean (point) and standard error (whiskers) of rosette numbers in the three network types.

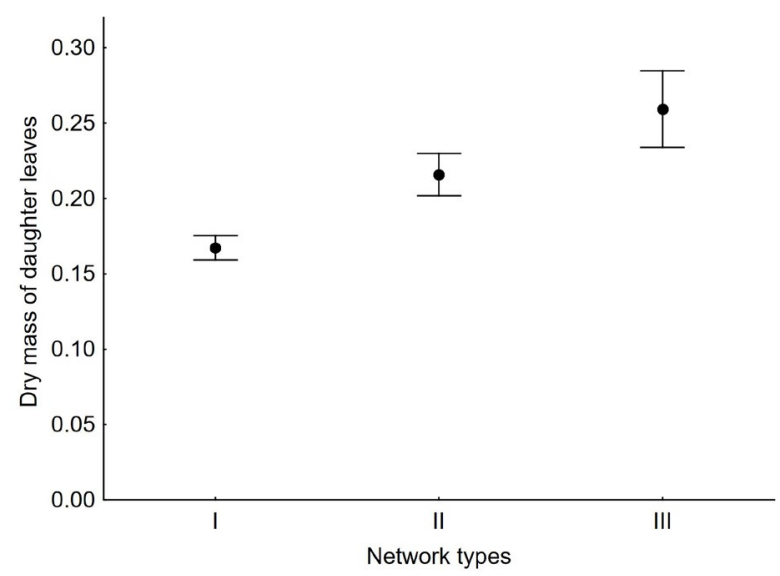

Figure 5. Mean (point) and standard error (whiskers) of daughter dry masses in the three network types.

clonal structure. The dry mass was also dependent on the network type (Tab. 2), and differences in dry mass were found only between types I and II (post hoc Tukey test $p=0.004$, Fig. 3 ). The case without any barriers to connection (type I) was characterized by a significantly higher number of rosettes than in type II (post hoc Tukey test $p=0.048$ ) and type III (post hoc Tukey test $p=0.020$, Fig. 4). In turn, the dry masses of daughters were lower in type I, and the differences between type I and the other types were significant (post hoc Tukey test $p=0.034$ for type II and $\mathrm{p}<0.001$ for type III, Fig. 5). The number of daughter flowers did not differ among network types (Tab. 2).

\section{Discussion}

The body of a clonal plant is a meta-holobiont sensu Vannier et al. (2019). It has a network structure that is composed of a mother plant and daughter ramets. The integration of ramets in a network is possible due to below- or aboveground connections between ramets (de Kroon \& van Groenendael 1997). Ramets acquire resources and share them. They can cooperate with one another (Stuefer et al. 1996; Alpert \& Stuefer 1997; Bittebiere et al. 2020). Additionally, networks of many clonal plants are interconnected with networks of AMF and other microorganisms (e.g., Streitwolf-Engel et al. 1997; Streitwolf-Engel et al. 2000; Liang et al. 2018; Vannier et al. 2018). A developing network expands and takes up an increasing amount of space. During network growth, ramets encounter different biotic and abiotic barriers that may damage network integrity. As a result, some changes in resource allocations to reproduction and ramet size may be expected.

Our experiment, in which we introduced artificial barriers to network integrity, showed that underground barriers between parental and daughter ramets affect their size and reproduction. This separation resulted in a decrease in the flower number in both types (type II and III) of ramets. The plants from experimental systems in which ramets lived within a common mycorrhizal network produced decidedly more inflorescences than ramets that were not included in such a network. Mycorrhizal fungi increase the availability of phosphorus to plants (Van Der Heijden et al. 2003; Vogelsang et al. 2006; Maiquetía et al. 2009), which activates the production of inflorescences (Campbell \& Halama 1993). Thus, the experimental ramets that lived within a common mycorrhizal network probably had access to higher amounts of phosphorus than the ramets that were not included in such a network.

Recently, some evidence has shown that runners may be effective vectors of fungal transfer between ramets in clonal plant networks (Vannier et al. 2016, 2018). This means of fungal spread in a network makes it possible for newly developed ramets to use additional phosphorus and other nutrients that affect the effectiveness of ramet sexual reproduction. The use of runners as the pathway for fungal and bacterial transfer may effectively affect ramet conditions and their survival (Zobel et al. 2010; Vannier et al. 2015). In the case of $H$. pilosella, the length and mass of runners depended significantly on the type of network. The longest and heaviest runners were produced in type II, i.e., when barriers between the mother and daughter ramets were introduced. Freedom in communication among ramets (type I) or its complete restriction resulted in the production of shorter and lighter ramets. Possibly, the importance of the runners functioning as information carriers (in the form of microorganisms and 
resources) changes depending on the abiotic environmental conditions in which a plant develops.

The separation of the underground resources available to mother and daughter ramets caused both types (II and III) of ramets at the onset of their development to have access to more resources, because these resources had not been previously depleted. Furthermore, with the growth of ramets, their root absorption zones may overlap. Thus, ramets may begin to compete for water and nutrients in the same area (Pechácková et al. 2003). This was indicated by the high dry mass of daughter leaves in the group (type I) with the lowest number of rosettes.

In summary, in this study, we experimentally interrupted clonal plant network integrity, i.e., we split a meta-holobiont sensu Vannier et al. (2019). Thus, we disturbed the resource allocation in the studied network and the transfer of a microorganism - the mycorrhizal fungus Rhizophagus irregularis - to consecutive generations, i.e., the daughter ramets. This resulted in the splitting of resource absorption zones. The split zones (sensu Harper 1986) did not overlap. Additionally, the mycorrhizal network supported the ramets in resource uptake. When the inter-ramet connections were interrupted, there was no resource sharing between these ramets. As expected, the amount of reproductive production (the number of mother flowers) and the development of clonal structure as determined by the number of rosettes were highest when all connections between ramets were preserved and supported by a mycorrhizal network. Contrary to our hypothesis, we observed a higher investment of resources into the size of particular plant components (the dry mass of runners and the dry mass of daughter ramets) and the development of the clonal structure (the length of runners) in the case of the interrupted inter-ramet connections than in the non-disturbed networks.

\section{Acknowledgements}

We thank Professor Zofia Szweykowska-Kulińska for permission to use the phytotron at the Institute of Molecular Biology and Biotechnology. We thank Professor Katarzyna Turnau for the AMF inoculum. We also thank the Botanical Garden of Adam Mickiewicz University in Poznan for the preparation of the steamed soil.

This study was supported by the statutory funds of the Department of Systematic and Environmental Botany of Adam Mickiewicz University in Poznań, Project No. 0200000000/604/505000/BN002018/S/PB/0-25.

\section{References}

Alpert, P. \& Stuefer, J. F. 1997. Division of labour in clonal plants. In: de Kroon H., van Groenendael J. (eds), The ecology and evolution of clonal plants. Backhuys Publishers, Leiden.

Beaumont, L. J., Gallagher, R. V., Thuiller, W., Downey, P. O., Leishman, M. R. \& Hughens, L. 2009. Different climatic envelopes among invasive populations may lead to underestimations of current and future biological invasions. Diversity and Distributions 15: 409-420. https://doi.org/10.1111/j.1472-4642.2008.00547.x

Bishop, G. F. \& Davy, A. J. 1985. Density and the commitment of apical meristems to clonal growth and reproduction in Hieracium pilosella L. Oecologia 66: 417-422. https://doi.org/10.1007/bf00378308
Bittebiere, A-K., Benot, M-L. \& Mony, C. 2020. Clonality as a key but overlooked driver of biotic interactions in plants. Perspectives in Plant Ecology, Evolution and Systematics 43: 125510. https://oi. org/10.1016/j.ppees.2020.125510

Campbell, D. R. \& Halama, K. J. 1993. Resource and pollen limitations to lifetime seed production in a natural plant population. Ecology 74: 1043-1051. https://doi.org/10.2307/1940474

Cassells, A. C., Mark, G. L. \& Periappuram, C. 1996. Establishment of arbuscular mycorrhizal fungi in autotrophic strawberry cultures in vitro. Comparison with inoculation of microplants in vivo. Agronomie 16: 625-632. https://doi.org/10.1051/agro:19961006

de Kroon, H. \& Van Groenendael, J. 1997. The Ecology and Evolution of Clonal Plants. Backhuys Publishers, Leiden.

Du, J., Yu, F-H, Alpert, P. \& Dong, M. 2009. Arbuscular mycorrhizal fungi reduce effects of physiological integration in Trifolium repens. Annals of Botany 104(2): 335-44. https://doi.org/10.1093/ $\mathrm{aob} / \mathrm{mcp} 130$

Fitter, A. H. \& Hay, R. K. M. 1989. Environmental physiology of plants. Academic Press, London.

Harper, J. L. 1977. Population Biology of Plants. Academic Press, New York.

Harper, J. L. 1986. Preface to 'Modular Organisms: Case Studies of Growth and Form. Papers relating to a discussion meeting on growth and form in modular organisms'. Proceedings of the Royal Society B. Biological Sciences 228: 111.

Huber, H. \& Stuefer, J. S. 1997. Shade-induced changes in the branching pattern of astoloniferous herb: functional response or allometric effect? Oecologia 13: 478-46.

Jackson, J. B. C., Cook, R. E. \& Buss, L. W. 1985. Population biology and evolution of clonal organisms. Yale University Press, New Haven.

Li, F., Xie, Y., Zhu, L., Jiang, L., Chen, X., Pan, B. \& Deng, Z. 2015. Changed clonal growth form induced by sand burial facilitates the acclimation of Carex brevicuspis to competition. PLOS ONE 10(3): e0121270. https://doi.org/10.1371/journal.pone.0121270

Liang, J-F., An, J., Gao, J-Q., Zhang, X-Y. \& Yu, F-H. 2018. Effects of arbuscular mycorrhizal fungi and soil nutrient addition on the growth of Phragmites australis under different drying rewetting cycles. PLoS ONE 13(1): e0191999. https://doi.org/10.1371/journal. pone.0191999

Lovett-Doust, L. 1981. Population dynamics and local specialization in a clonal plant Ranunculus repens. I. The dynamics of ramets in contrasiting habitats. Journal of Ecology 69: 743-755. https://doi. org $/ 10.2307 / 2259633$

Maiquetía, M., Cáceres, A. \& Herrera, A. 2009. Mycorrhization and phosphorus nutrition affect water relations and CAM induction by drought in seedlings of Clusia minor. Annals of Botany 103: 525-532. https://doi.org/10.1093/aob/mcn238

McCullagh, P. \& Nelder, J. A. 1989. Generalized Linear Models, $2^{\text {nd }}$ Ed. Chapman and Hall, New York.

Miller, R. M., Miller, S. P., Jastrow, J. D. \& Rivetta, C. B. 2002. Mycorrhizal mediated feedbacks influence net carbon gain and nutrient uptake in Andropogon gerardii. New Phytologist 155: 149-162. https://doi.org/10.1046/j.1469-8137.2002.00429.x

Noble, J. C., Bell, A. D. \& Harper, J. L. 1979. The population biology of plants with clonal growth: I. The morphology and structural demography of Carex arenaria. Journal of Ecology 67(3): 983-1008. https://doi.org/10.2307/2259224

Pecháčková, S., Albrechtová, M., Hadincová, V., Krahulec, F. \& Herben, T. 2003. Horizontal and vertical distribution of root absorption zones of four common grass species in a mountain grassland. New Phytologist 161(1): 303-312. https://doi.org/10.1046/j.14698137.2003.00909.x

Pirożnikow, E. 1993. Populations of Saxifraga oppositifolia L., in Spitsbergen tundra in different ecological conditions. Polish Polar Research 14(4): 355-382. 
Smith, S. E. \& Read, D. J. 2008. Mycorrhizal Symbiosis. Academic Press, San Diego.

StatSoft Inc. 2018. Statistica, data analysis software system, version 12.0, www.statsoft.com.

Streitwolf-Engel, R., Boller, T., Wiemken, A. \& Sanders, I. R. 1997. Clonal growth traits of two Prunella species are determined by co-occurring arbuscular mycorrhizal fungi from a calcareous grassland. Journal of Ecology 85: 181-191.

Streitwolf-Engel, R., Van der Heijden, M. G. A., Wiemken, A. \& Sanders, I. R. 2000. The ecological significance of arbuscular mycorrhizal fungal effects on clonal reproduction in plants. Ecology 82: 2846-2859. https://doi.org/10.2307/2960650

Stuefer, J. F., de Kroon, H. \& During, H. J. 1996. Exploitation of environmental heterogeneity by spatial division of labour in a clonal plant. Functional Ecology 10: 328-334. https://doi.org/10.2307/2390280

Sudová, R. 2009. Different growth response of five coexisting stoloniferous plant species to inoculation with native arbuscular mycorrhizal fungi. Plant Ecology 204: 135-143. https://doi.org/10.1007/ s11258-009-9576-5

Sudová, R. \& Vosátka, M. 2008. Effects of inoculation with native arbuscular mycorrhizal fungi on clonal growth of Potentilla reptans and Fragaria moschata (Rosaceae). Plant and Soil 308: 55-67. https://doi.org/10.1007/s11104-008-9605-5

Van Der Heijden, M. G., Wiemken, A. \& Sanders, I. R. 2003. Different arbuscular mycorrhizal fungi alter coexistence and resource distribution between co-occurring plant. New Phytologist 157: 569-578. https://doi.org/10.1046/j.1469-8137.2003.00688.x

van Groenendael, J. \& de Kroon, H. 1990. Clonal Growth in Plants: Regulation and Function. SPB Academic Publishing, Amsterdam.
Vannier, N., Mony, C., Bittebière, A-K. \& Vandenkoornhuyse, P. 2015 Epigenetic mechanisms and microbiota as a toolbox for plant phenotypic adjustment to environment. Frontiers in Plant Science 6: 1159. https://doi.org/10.3389/fpls.2015.01159

Vannier, N., Bittebiere, A. K., Vandenkoornhuyse, P. \& Mony, C. 2016. AM fungi patchiness and the clonal growth of Glechoma hederacea in heterogeneous environments. Scientific Reports 6: 37852. https:// doi.org/10.1038/srep37852

Vannier, N., Mony, C., Bittebiere, A-K., Michon-Coudouel, S. \& Biget, M., Vandenkoornhuyse, P. 2018. A microorganisms' journey between plant generations. Microbiome 6: 79. https://doi.org/10.1186/ s40168-018-0459-7

Vannier, N., Mony, C., Bittebiere, A-K., Theis, K. R., Rosenberg, E. \& Vandenkoornhuyse, P. 2019. Clonal plants as meta-holobionts. mSystems 4: e00213-18. https://doi.org/10.1128/mSystems.00213-18

Varma, A. \& Schüepp, H. 1994. Infectivity and effectiveness of Glomus intraradices on micropropagated plants. Mycorrhiza 5(1): 29-37. https://doi.org/10.1007/BF00204017

Vogelsang, K. M., Reynolds, H. L. \& Bever, J. D. 2006. Mycorrhizal fungal identity and richness determine the diversity and productivity of a tallgrass prairie system. New Phytologist 172: 554-562. https:// doi.org/10.1111/j.1469-8137.2006.01854.X

Wang, B. \& Qiu, Y-L. 2006. Phylogenetic distribution and evolution of mycorrhizas in land plants. Mycorrhiza 16(5): 299-363. https:// doi.org/10.1007/s00572-005-0033-6

Zobel, M., Moora, M. \& Herben, T. 2010. Clonal mobility and its implications for spatio-temporal patterns of plant communities: what do we need to know next? Oikos 119: 802-806. https://doi. org/10.1111/j.1600-0706.2010.18296.x 